\title{
Observation on the clinical effects of humanistic nursing on the psychological status of patients with COPD in acute phase.
}

\author{
Xiao-Yan Wang ${ }^{1}$, Ling-Hua Liu ${ }^{2 *}$ \\ ${ }^{1}$ Department of Nursing, Baoji Central Hospital, Baoji, Shaanxi, PR China \\ ${ }^{2}$ Department of Respiratory Medicine, Shaanxi Provincial People's Hospital, Xi'an, Shaanxi, PR China
}

\begin{abstract}
Objectives: This study aimed to explore the clinical effects of humanistic nursing on patients with Chronic Obstructive Pulmonary Disease (COPD) in the acute phase.

Methods: The random number table was adopted to divide 120 patients into for the control group $(n=60)$ and the test group $(n=60)$. These patients had COPD in the acute phase, and they received medical treatment from May 2016 to August 2017 in the hospital where the author worked. Routine nursing was provided to the control group, whereas humanistic nursing was given to the test group. Then, the two groups of patients were comparatively analysed in terms of psychological status, duration of clinical symptom remission, pulmonary functions, quality of life, and nursing satisfaction degree.

Results: The depression and anxiety scoring of the test group was significantly lower than that of the control group $(\mathbf{P}<\mathbf{0 . 0 5})$. The duration of body temperature decrease, asthma remission, and coughing remission of the test group were significantly shorter than that of the control group $(P<0.05)$. As compared with the control group, the test group scored significantly higher in terms of Forced Vital Capacity (FVC), Forced Expiratory Volume in one second (FEV1), Maximum Mid-Expiratory Flow volume (MMFF), material life, physical functions, psychological functions, social functions, and nursing satisfaction $(\mathbf{P}<\mathbf{0 . 0 5})$.

Conclusions: The clinical effects of humanistic nursing on patients with COPD in acute phase were significant. With humanistic nursing, patients with COPD in acute phase could obtain their psychological status, and their pulmonary function effectively improved; they took shorter time to recover from clinical symptoms, lived a high quality of life, and showed a high satisfaction degree for the nursing. All these positive clinical effects suggested that humanistic nursing is worthy of further promotion and application in the clinical treatment of patients with COPD in the acute phase.
\end{abstract}

Keywords: COPD, Humanistic nursing, Psychological status, Quality of life.

Accepted on October 24, 2017

\section{Introduction}

Chronic Obstructive Pulmonary Disease (COPD) is a common respiratory system disease prevalent among elders. In recent years, the prevalence of COPD has been rising annually [1]. In the acute phase of COPD, the state of the illness worsens, thereby leading to the degradation of the pulmonary function of patients, increasing their negative emotions, and decreasing their quality of life $[2,3]$. These problems become increasingly prominent and have necessitated the provision of comprehensive and considerate nursing services to help patients improve their psychological status, clinical symptoms, pulmonary function, and quality of life [4]. A clinical research was conducted on 120 patients with COPD in the acute phase who received treatment from May 2016 to August 2017 in the hospital where the author worked. The clinical effects of humanistic nursing on these patients were analysed.

\section{Materials and Methods}

\section{Materials}

A total of 120 patients with COPD in the acute phase received treatment from May 2016 and August 2017 in the hospital where the author worked. These patients were divided into the control group $(n=60)$ and the test group $(n=60)$ using the random number table. In the control group, 40 were male patients, and 20 were female patients. Their age, which ranged from $55 \mathrm{y}$ old to $83 \mathrm{y}$ old, averaged at $66.4 \pm 7 \mathrm{y}$ old, and the course of their disease ranged from 5 to $17 \mathrm{y}(11.4 \pm 1.9 \mathrm{y}$ on average). In the test group, 30 were male patients and 22 were female patients. Their ages, which ranged from 54 to $85 \mathrm{y}$ old, averaged at $67.1 \pm 1.8 \mathrm{y}$ old. SPSS 22.0 was employed to analyse the abovementioned data of the two groups, which showed no intergroup significant difference $(\mathrm{P}>0.05)$. 


\section{Methods}

Hospitalization nursing: After the patients were admitted to the hospital, the nursing personnel patiently served the patients. The nursing personnel introduced the patient and his or her family members to the hospital environment, regulations, and systems to eliminate the sense of inadaptability and tension of the patients. They assisted the patients in processing various checks.

Psychological nursing: COPD is characterized by a long course of disease, recurrence, and difficulty of getting cured. The characteristics of the disease led to the development of negative emotions, including depression and anxiety, during the course of disease. Therefore, the nursing personnel must actively communicate with patients, learn their psychological demands, provide them targeted guidance, and help them build confidence during treatment. Meanwhile, the family members should accompany the patients and provide them more care to cheer them up and thereby actively cooperate with the medical treatment.

Environmental nursing: The indoor temperature was maintained between $22^{\circ} \mathrm{C}$ and $25^{\circ} \mathrm{C}$, and the moisture was between $50 \%$ and $60 \%$. The ward was kept quiet and tidy. The windows were regularly opened to ensure good ventilation and to let more fresh air and sunlight in. The bedside height of the patients was properly adjusted to guarantee good rest.

Health education: The nursing personnel introduced to patients in simple language the relevant knowledge of COPD, including the pathogenic mechanism, pathogenic rule, prevention, and treatment of the disease to deepen their understanding, improve their awareness of self-protection, enhance compliance behaviors, and stimulate them to actively cooperate with treatment and nursing.

\section{Observation indexes}

Psychological state: The Self-Rating Depression Scale (SDS) and Self-Rating Anxiety Scale (SAS) were used to evaluate the degree of depression and anxiety of patients from 0 point to 100 points with the clinical value of 50 points. Slight anxiety and depression ranked from 50 points to 60 points. Medium anxiety and depression ranked from 61 points to 70 points. High scores indicated poor psychological status.

Pulmonary function: The evaluation indexes of pulmonary function included four dimensions, namely, material life, physical functions, psychological functions, and social functions. The value of every dimension ranged from 0 point to 100 points. High scores indicated improvement in the quality of life.

Nursing satisfaction degree: The self-designed questionnaire was used to evaluate the satisfaction degree of nursing of the patients, which ranged from 0 point to 100 points. If the satisfaction degree was above 90 points, a patient was strongly satisfied with the nursing service. If the satisfaction degree scores were between 60 (inclusive) and 90 (inclusive) points, the patient was generally satisfied with the nursing service. If the satisfaction degree was below 60 points, the patient was unsatisfied with the nursing service. The sum of the strong satisfaction degree and the general satisfaction degree was the overall satisfaction degree of the nursing service.

\section{Statistical analysis}

SPSS 22.0 was used to analyse the observational data of the two groups of patients. The measurement data (including the scoring of depression, anxiety, body temperature decrease, the duration of asthma remission, the duration of coughing remission, FVC, FEV1, MMFF, material life, physical functions, psychological functions, and social functions) are presented as $(\overline{\mathrm{x}} \pm \mathrm{S})$, and t-test was conducted. The enumeration data (nursing satisfaction degree) was written in the form of percentage, and then, $\chi^{2}$-test was performed. If $\mathrm{P}<0.05$, the two groups were significantly different from each other in terms of measurement data and enumeration data.

\section{Results}

\section{Comparative analysis of psychological status}

The patients in the test group scored significantly lower than the patients in the control group $(\mathrm{P}<0.05$, Table 1$)$.

Table 1. Comparative analysis of psychological status of patients in two groups $(\bar{x} \pm S$, point $)$.

\begin{tabular}{lll}
\hline Group & Depression scoring & Anxiety scoring \\
\hline Test group $(n=60)$ & $33.7 \pm 5.8$ & $32.3 \pm 5.6$ \\
\hline Control group $(n=60)$ & $53.4 \pm 5.2$ & $52.3 \pm 5.1$ \\
\hline T-value & 19.5893 & 20.4532 \\
\hline P-value & 0.0000 & 0.0000 \\
\hline
\end{tabular}

\section{Comparative analysis of duration of clinical symptom remission}

The duration of the body temperature decrease, asthma remission, and coughing remission of the patients in the test group was significantly shorter than that in the control group $(\mathrm{P}<0.05$, Table 2$)$.

Table 2. Comparative analysis of duration of clinical symptom remission of patients in two groups $(\bar{x} \pm S, d)$.

\begin{tabular}{llll}
\hline Group & $\begin{array}{l}\text { Duration of body } \\
\text { temperature } \\
\text { decrease }\end{array}$ & $\begin{array}{l}\text { Duration } \\
\text { asthma } \\
\text { remission }\end{array}$ & $\begin{array}{c}\text { of } \\
\begin{array}{l}\text { Duration } \\
\text { coughing } \\
\text { duration }\end{array}\end{array}$ \\
\hline Test $(n=60)$ & $4.3 \pm 0.7$ & $5.4 \pm 1.8$ & $8.3 \pm 2.5$ \\
\hline Control $(n=60)$ & $6.5 \pm 0.7$ & $7.7 \pm 2.0$ & $11.4 \pm 2.0$ \\
\hline T-value & 17.2141 & 6.6211 & 7.5002 \\
\hline P-value & 0.0000 & 0.0000 & 0.0000 \\
\hline
\end{tabular}



phase

\section{Comparative analysis of pulmonary function}

The FVC, FEV1, and MMEF of patients in the test group were significantly higher than in the control group $(\mathrm{P}<0.05$, Table 3$)$.

Table 3. Comparative analysis of pulmonary function of patients in two groups $(\bar{x} \pm S)$.

\begin{tabular}{llll}
\hline Group & FVC $(L)$ & FEV1 (L) & MMEF (L/s) \\
\hline Test group $(n=60)$ & $2.1 \pm 0.4$ & $1.7 \pm 0.3$ & $1.4 \pm 0.2$ \\
\hline Control group $(n=60)$ & $1.5 \pm 0.2$ & $1.1 \pm 0.2$ & $1.0 \pm 0.1$ \\
\hline T-value & 10.3923 & 12.8900 & 13.8564 \\
\hline P-value & 0.0000 & 0.0000 & 0.0000 \\
\hline
\end{tabular}

\section{Comparative analysis of quality of life}

The scoring of the test group was much higher than that of the control group in terms of material life, physical functions, psychological functions, and social functions $(\mathrm{P}<0.05$, Table 4).

Table 4. Comparative analysis of quality of life of patients in two groups $(\bar{x} \pm S$, point $)$

\begin{tabular}{|c|c|c|c|c|}
\hline Group & Material life & $\begin{array}{l}\text { Physical } \\
\text { functions }\end{array}$ & $\begin{array}{l}\text { Psychologic } \\
\text { al functions }\end{array}$ & $\begin{array}{l}\text { Social } \\
\text { functions }\end{array}$ \\
\hline $\begin{array}{l}\text { Test } \\
(n=60)\end{array}$ & $88.6 \pm 6.4$ & $88.7 \pm 6.2$ & $90.4 \pm 6.1$ & $89.8 \pm 6.5$ \\
\hline $\begin{array}{l}\text { Control group } \\
(n=60)\end{array}$ & $75.2 \pm 5.5$ & $74.5 \pm 5.4$ & $76.7 \pm 6.5$ & $76.3 \pm 5.7$ \\
\hline T-value & 12.3001 & 13.3779 & 11.9047 & 12.0957 \\
\hline P-value & 0.0000 & 0.0000 & 0.0000 & 0.0000 \\
\hline
\end{tabular}

\section{Comparative analysis of satisfaction degree of nursing service}

The satisfaction degree of the nursing service was $93.3 \%$ in the test group, which was significantly higher than that of the control group, which was $73.3 \%$; $(\mathrm{P}<0.05$, Table 5).

Table 5. Comparative analysis of satisfaction degree of nursing service $(n(\%))$.

\begin{tabular}{lllll}
\hline Group & $\begin{array}{l}\text { Strongly } \\
\text { satisfied }\end{array}$ & Satisfied & Dissatisfied & $\begin{array}{l}\text { Overall } \\
\text { satisfaction } \\
\text { degree }\end{array}$ \\
\hline $\begin{array}{l}\text { Test group } \\
(\mathrm{n}=60)\end{array}$ & $31(51.7)$ & $25(41.7)$ & $4(6.7)$ & $56(93.3)$ \\
\hline $\begin{array}{l}\text { Control } \\
\text { group }(\mathrm{n}=60)\end{array}$ & $17(28.3)$ & $27(45.0)$ & $16(26.7)$ & $44(73.3)$ \\
\hline $\mathrm{X}^{2}$-value & & & \\
\hline P-value & & & 8.6400 \\
\hline
\end{tabular}

\section{Discussion}

COPD is a chronic respiratory disease with a high prevalence and death rate and is commonly found among elders. Due to degradation of physical functions, elders often suffer from not only COPD but also from several other diseases that develop with aging [5]. When their respiratory tract defense function is destroyed, the immunity of their body also deteriorates, thereby leading to recurrence of COPD. Furthermore, COPD has a long course of disease, which can seriously influence the quality of life of patients [6,7]. The majority of patients also suffer from some negative emotions, which are notably depression and anxiety. This condition has to some extent impaired clinical treatment effects.

Humanistic nursing emerges as a new nursing model according to the "human-oriented" concept. While maximally satisfying the nursing demands of patients, humanistic nursing can also improve the nursing experience, satisfaction degree, and quality of life of patients [8,9]. Humanistic nursing, including psychological nursing, environmental nursing, health education, and symptomatic nursing, was performed on the patients with COPD in acute phase in this study. First, psychological nursing could be effectively alleviated through psychological nursing to minimize the psychological pressure of patients and stimulate them to actively cooperate with the medical treatment and nursing. Second, environmental nursing could help patients relax, both physically and mentally. Third, health education could increase the knowledge of patients with COPD. Fourth, symptomatic nursing could alleviate the clinical symptoms of patients, improve their quality of life, and help them achieve favorable treatment and prognostic effects. Findings of this paper suggested that the test group was significantly superior to the control group in terms of psychological status, duration of clinical symptom remission, pulmonary function, quality of life, and nursing satisfaction degree of patients $(\mathrm{P}<0.05)$. These findings also showed good agreement with the research results of previous scholars [10], thereby further substantiating the superiority of humanistic nursing to routine nursing and suggesting that humanistic nursing is worthy of further promotion in clinical treatment.

\section{Conclusion}

To sum up, the clinical effects of humanistic nursing are significant to patients with COPD in acute phase. With humanistic nursing, patients with COPD in acute phase can improve in terms of psychological status and pulmonary function, thereby shortening their time of recovery from clinical symptoms and leading to a high quality of life. A high satisfaction degree of nursing was also observed. All these positive clinical effects suggest that humanistic nursing is worthy of further promotion and application in the clinical treatment of patients with COPD in the acute phase. 


\section{References}

1. He Y, Liu S, Zhang Z, Liao C, Lin F, Yao W, Chen Y. Imbalance of endogenous hydrogen sulfide and homocysteine in chronic obstructive pulmonary disease combined with cardiovascular disease. Front Pharmacol 2017; 8: 624.

2. Zhu LM, Lin P, Dai T, Zhang CH, Ma RP. Docking study of cardiovascular diseases treatment drugs salvianolic acid A and $\mathrm{C}$ into the activity cavity of intestinal UDPGlucuronosyltransferase (UGT) 1A8. Lat Am J Pharm 2017; 36: 179-183.

3. Fan W, Lee H, Lee A, Kieu C, Wong ND. Association of lung function and chronic obstructive pulmonary disease with American Heart Association's Life's Simple 7 cardiovascular health metrics. Respir Med 2017; 131: 85-93.

4. Li X, Dong X, Zhang L, Ni J. An Investigation into the role of surfactants in controlling particle size and entrapment efficiency of nanoparticles loaded with water insoluble drug. Lat Am J Pharm 2016; 35: 1122-1129.

5. Crim C, Calverley PMA, Anderson JA, Holmes AP, Kilbride S, Martinez FJ, Brook RD, Newby DE, Yates JC, Celli BR, Vestbo J. Pneumonia risk with inhaled fluticasone furoate and vilanterol in COPD patients with moderate airflow limitation: The SUMMIT trial. Respir Med 2017; 131: 27-34.

6. Amr AEGE, Abdalla MM. Anticancer activities of some synthesized 2, 4, 6-trisubstituted pyridine candidates. Biomed Res India 2016; 27: 731-736.
7. Goto T, Faridi MK, Gibo K, Camargo CA Jr, Hasegawa K. Sex and racial/ethnic differences in the reason for 30-day readmission after COPD hospitalization. Respir Med 2017; 131: 6-10.

8. Elizabeth G, Glan Devadas G, Avinashe KK, Sudharsana V. Study of different spectral parameters to measure depth of anesthesia. Biomed Res India 2017; 28: 6533-6540.

9. Yang Y, Mao J, Ye Z, Li J, Zhao H, Liu Y. Risk factors of chronic obstructive pulmonary disease among adults in Chinese mainland: A systematic review and meta-analysis. Respir Med 2017; 131: 158-165.

10. Prins HJ, Duijkers R, Lutter R, Daniels JM, van der Valk P, Schoorl M, Kerstjens HA, van der Werf TS, Boersma WG. Blood eosinophilia as a marker of early and late treatment failure in severe acute exacerbations of COPD. Respir Med 2017; 131: 118-124.

\section{*Correspondence to}

Ling-Hua Liu

Department of Respiratory Medicine

Shaanxi Provincial People's Hospital

PR China 